\title{
Influencing Factors of Plastic Waste Pollution Reduction in Kinshasa
}

\author{
Orphe Tshinkobo Bukasa1 (ㄹ, Diana Iskakova2 ${ }^{2}$, , Sherif Abdul Ganiyu2 ${ }^{2}$ (), \\ Xing Rong1, Meng Li1, Jianjun Li ${ }^{*}$
}

\author{
${ }^{1}$ School of Materials Science and Engineering, Anhui University of Science and Technology, Huainan, China \\ ${ }^{2}$ School of Economics and Management, Anhui University of Science and Technology, Huainan, China \\ Email: orpheted@gmail.com, diana250570@yandex.ru, abdulganiyusherif1@gmail.com, \\ 29478554082@qq.com,1579080621@qq.com, *lijj3@aust.edu.cn
}

How to cite this paper: Bukasa, O. T., Iskakova, D., Ganiyu, S. A., Rong, X., Li, M., \& Li, J. J. (2020). Influencing Factors of Plastic Waste Pollution Reduction in Kinshasa. Journal of Geoscience and Environment Protection, 8, 180-199. https://doi.org/10.4236/gep.2020.812011

Received: November 26, 2020

Accepted: December 21, 2020

Published: December 24, 2020

Copyright $\odot 2020$ by author(s) and Scientific Research Publishing Inc. This work is licensed under the Creative Commons Attribution International License (CC BY 4.0).

http://creativecommons.org/licenses/by/4.0/ (c) (i) Open Access

\begin{abstract}
Plastic products, e.g., plastic bags, plastic bottles, and other plastic materials are widely used in people's daily life and industrial production worldwide since they are cheap, easy to get, and convenient for all-purpose of transportation or movement. The wide application of plastic products also brings a lot of problems. The significant adverse consequences include plastic waste pollution and waste of resources, which pose a high threat to social development and environmental protection. In this research, a social survey involving 267 people was conducted to examine how certain factors reduce plastic waste pollution in Kinshasa. Statistical Product and Service Solutions were employed to analyze the data gathered from the survey. The results indicate that all the factors or strategies for reducing plastic waste pollution have a significant positive impact on plastic waste pollution reduction. The environmental factors have the highest contribution to the control of plastic waste pollution with an impact of $88.8 \%$, followed by Government policy with an impact of 42.3\%. Economic factors have the least impact contribution, with an impact of $36.0 \%$. This finding and conclusion could be used as a framework for implementing plastic waste pollution management strategies or developing waste management systems.
\end{abstract}

\section{Keywords}

Plastic Waste, Pollution, Waste Management Systems, Kinshasa, Statistical Product, Service Solutions

\section{Introduction}

Plastic materials are the most prevalent means of carriage in Kinshasa. This can 
attribute to the widespread usage of plastic materials as means of carriage to its cheapness, lightweight, and convenience. A large amount of these plastic materials is discarded after a single-use. It estimates that more than 12 million people use at least one plastic material per day in DR Congo. (RFI, 2019) and 40\% of these plastic materials are single-use (BBC, 2020).

Worldwide, plastic contamination has exceeded pandemic proportions, with the vast amounts of plastic waste posing significant threats to environmental health both on land and in the oceans. It's even a threat to human health as microplastics have permeated our food and water and our table salt. We can do little about the vast amounts of plastic already in the oceans, but we can still do a lot to ensure we won't be adding much more plastic waste to that already out there (Parker, 2018; Moore, 2020).

It is estimated that its 17 million inhabitants known as "Kinois," produce around 9,000 tons of garbage daily. The absence of professional waste management systems has contributed to the worsening garbage situation in Kinshasa as shown in Figure 1.

Dozens of people in the DRC are reported dead annually due to flooding caused by choked rivers and sewage systems with plastic debris and materials (Aljazeera, 2018). Rivers and streams are clogged with plastic waste materials posing various health and environmental hazards to Kinois. It is estimated that 1500 tons of plastic waste is produced in Kinshasa, representing about $15 \%$ of all accumulated waste. Jambeck et al. (2015) report that DRC contributes nearly $0.05 \%$ of global plastic waste in oceans.

Over the past years, waste management services of Kinshasa City have been funded by the European Union (E.U.) through the PARAU PROJECT (Projet d'Appui et de Réhabilitation des Infrastructures Routières en RDC et d'Amélioration de l'Assainissement Urbain de Kinshasa). Currently, the project has ended, and waste pollution in the city has increased over time due to lack of financial resources and adequate waste management systems.

In 2018, the government, in an attempt to eliminate the detrimental effects of plastic waste pollution in Kinshasa, banned the manufacturing and sale of plastic materials such as bags and bottles, but can still be imported. The implementation of this ban is still in limbo as plastic waste is still increasing with its adverse consequences, such as flooding and the health conditions of Kinois. A National Sanitation Policy (Politique Nationale d'Assainissement, PNA) was also formulated in 2013 to tackle the increasing rate of plastic waste pollution; however, this policy has not been enforced due to a lack of financial resources and waste management infrastructures.

The increasing rate of plastic waste pollution in DRC cannot be overlooked. Therefore, it calls for more research to examine the factors that can be implemented to control plastic waste pollution in Kinshasa. This research examines the critical factors necessary for reducing or eliminating plastic waste pollution in Kinshasa and adding to plastic waste management literature. This research 


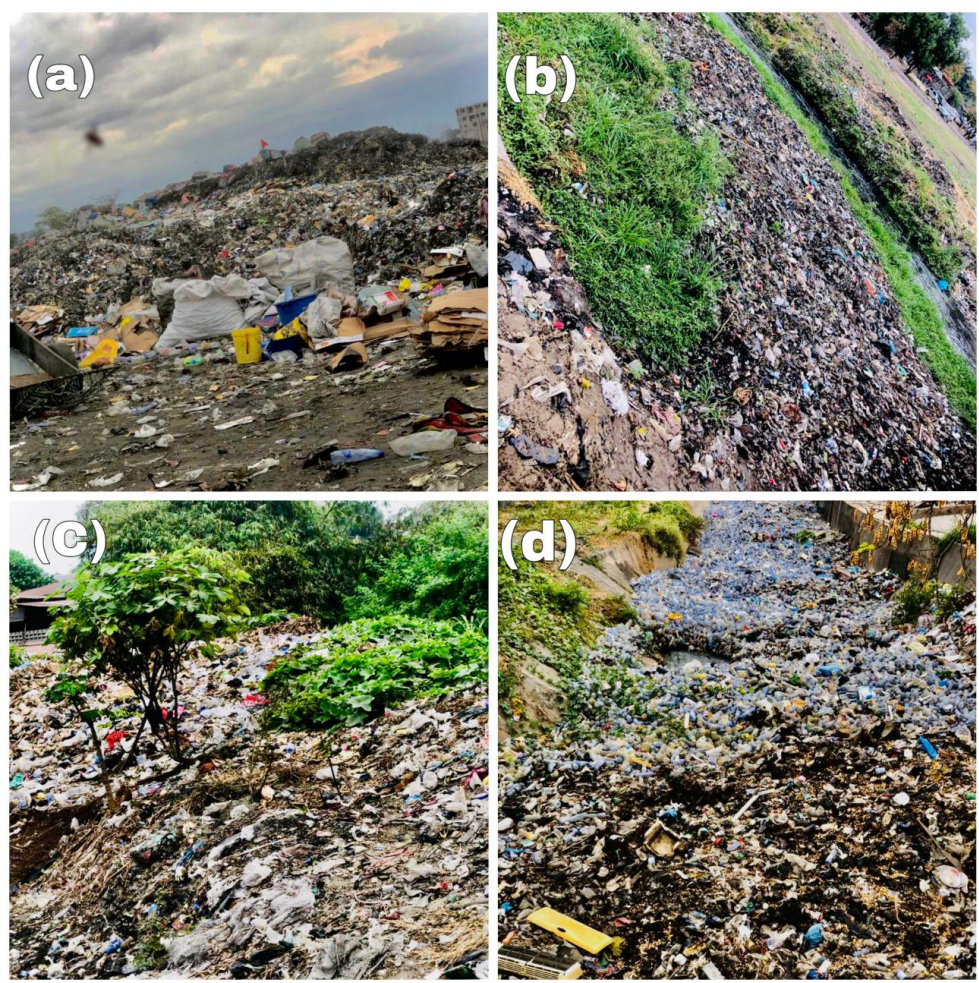

Figure 1. (a) Pile of plastic trash at Kasavubu, Banalia Avenue, Kinshasa (b) Plastic mismanagement at $1^{\text {st }}$ street, Limete Avenue, Kinshasa (c) No dustbin at Kalamu, Bumbu Avenue, Kinshasa (d) Drainage channel are blocked on Sendwe Boulevard, Lingwala Avenue, kalamu river, Kinshasa.

can be used as a guideline by policymakers to formulate efficient and effective waste management strategies.

\section{Informing Literature on Plastic Waste Pollution}

Plastic pollution is the concentration of plastic products and particles in the Earth's atmosphere (e.g., plastic bottles, bags, and microbeads) that adversely impact ecosystems, natural habitats, and humans. Plastics that act as contaminants are classified according to size into micro-, meso, or macro debris (Hammer et al., 2012).

Plastics are inexpensive and robust, resulting in high rates of plastic production by humans. According to (Chadar \& Keerti, 2017), Wastes are the materials that are not economically useable with further processing.

In 1907, the first synthetic plastic, known as Bakelite, was produced. However, this plastic's mass production was realized in the 1950s due to the global plastic industry's expansion and industrialization. As of 2018, about 400 million tons of plastics are manufactured annually worldwide (BBC, 2020). From the 1950s to 2018, an estimated 6.3 billion tons of plastic were processed worldwide, an estimated 9 percent of which was recycled and an additional 12 percent incinerated (Hester et al., 2011). This vast volume of plastic waste reaches the atmosphere, with reports indicating that 90 percent of seabirds contain plastic debris (Hester 
et al., 2011; Hermabessiere et al., 2017). Some marine pollution experts say that there might be more plastic than fish in the sea by 2050. A report indicates that about 100,000 aquatic animals are killed by plastic waste annually (BBC, 2020). Several researchers have documented the impact of plastic waste on human health (Revel et al., 2018; Galloway, 2015), the environment, ecosystem (Rochman et al., 2016; Law, 2017; Kühn et al., 2015), and wildlife (Gall \& Thompson, 2015; Güven et al., 2017).

The impact or dangers that plastic waste pollution poses to countries cannot be overlooked. Over the years, high-income nations such as most European nations, Australia, New Zealand, Norway, Sweden, UK, Japan, and South Korea have sorted recycling to reduce the impact of plastic waste pollution on their economies. These countries have invested in developing efficient and effective waste management infrastructure and systems; however, these countries contribute to global plastic waste pollution through littering (Jambeck et al., 2015). Most developing African nations lack adequate infrastructures and systems to manage the increasing rate of waste pollution and, therefore, suffer pollution heavily.

More than 8 million tons of plastic waste materials enter the world's oceans each year, and $80 \%$ of the plastic waste materials escape from the mainland, and the rest are from marine sources (Li et al., 2016). East Asia and Pacific regions contribute nearly $60 \%$ of global mismanaged plastic waste, whereas the Sub-Saharan contribute about $8.9 \%$. China, as the highest contributor to plastic waste pollution globally (Wang et al., 2018), has contributed about $28 \%$ of global plastic waste materials in Oceans, followed by Indonesia with $10 \%$. The highest contributors from Sub-Saharan Africa are Egypt, Nigeria, with 3\% and 2.7\%, respectively. DRC was reported to contribute $0.05 \%$ to global plastic waste in oceans (Jambeck et al., 2015). Eriksen et al. (2014) found out that approximately 269,000 tons of plastic waste particles exist in surface waters globally.

The extent of plastic contamination is defined mainly by a wide variety of plastic goods. In our everyday lives, thousands of plastic items are in demand on the global market. E.g., P.E. (polyethylene), P.P. (polypropylene), PVC (polyvinylchloride), PET (polyethylene terephthalate), and P.S. (polystyrene) are the most commonly used plastics on the market (Bond et al., 2018). Given different forms of plastics, their regular applications were mixtures, consisting mostly of monomers, oligomers, and additives (Hermabessiere et al., 2017).

Plastic pollution origins were also problematic, arising primarily from combinations of anthropogenic practices. It has been reported that plastics can enter marine, terrestrial, and atmospheric environments directly or indirectly through different mechanisms, such as mismanaged plastic Waste, wastewater treatment plants, domestic sewage, landfills, agricultural or even industrial dust (Law, 2017; Ziajahromi et al., 2017; Windsor et al., 2019; Bai \& Li, 2020), which suggest that plastics origins are complex, too. Similarly, in the field, plastics were also varied in color, scale, and form. Nevertheless, both the deterioration and accu- 
mulation of plastics remain unknown in the atmosphere due to a lack of conventional analytical techniques or appropriate instruments. These diversities are likely to result in the complexity of environmental plastic emissions, making it impossible to establish consistent and coherent methodological approaches, thereby restricting functional studies' creation. There is a strong need for more work to appreciate the toxic plastic emissions better.

We see some other worrying trends. Since the 1950s, the rate of plastic production has grown faster than that of any other material. We've also seen a shift away from durable plastic production and towards plastics that are meant to be thrown away after a single-use. More than $99 \%$ of plastics are produced from chemicals derived from oil, natural gas, and coal—all of which are dirty, nonrenewable resources. If current trends continue, by 2050, the plastic industry could account for $20 \%$ of the world's total oil consumption.

Only $9 \%$ of all plastic waste ever produced has been recycled. About $12 \%$ have been incinerated, while $79 \%$ have accumulated in landfills, dumps, or the natural environment. Cigarette butts whose filters contain tiny plastic fibers were the most common type of plastic waste found in the environment in a recent global survey. Drink bottles, bottle caps, food wrappers, grocery bags, drink lids, straws, and stirrers were the next most common items. Many of us use these products every day, without even thinking about where they might end up (UN Environment Report, 2018).

\subsection{Impacts of Plastic}

Plastics pose a significant threat to ocean and freshwater ecosystems and the benefits humans receive from them. The amount of plastic debris discarded by the commercial fishing industry has doubled over the last 50 years (from 340,000 tons in 1975 to 640,000 tons annually) (Bender, 2018).

Plastics threaten the survival of many species of wildlife, negatively impacting nearly 700 species worldwide (Bender, 2018).

1) Larger items, such as fishing nets, intertwine and destroy wildlife (Gregory, 2009).

2) Smaller items ingested by wildlife lower fitness by decreasing fertility (Bender, 2018).

3) Plastic debris can hold toxins, increase their environmental persistence, and accumulate organic pollutants up to 106 times that of the surrounding seawater (Moore, 2008). Chemicals found in plastic waste, such as PCBs, cause reproductive disorders or death, enhance disease risk, and alter hormone levels (UNEP, NOAA, 2011).

\subsection{Plastic Pollution in the DRC}

Once a fishing and trading place, Kinshasa is now a megacity with an estimated more than 17 million population. (Géographie de Kinshasa, 2012) It faces Brazzaville, the capital of the neighboring Republic of Congo, which we can see from 
afar across the broad Congo River. After the Nile, the Congo River is the secondlongest river in Africa and has the most massive discharge. It provides a means of transportation for much of the Congo basin as a waterway; it is navigable for river barges between Kinshasa and Kisangani; many of its tributaries are navigable.

Kinshasa is the third-largest urban region of Africa after Cairo and Lagos (Dermographia, 2020).

Plastic pollution is a more than apparent reality in the Democratic Republic of Congo, DRC. The DRC produces 48,154 kilos of plastic per day, $85 \%$ of which are poorly managed (UN Environment Report, 2018). Kinshasa's 12 million inhabitants produce 7000 tons of waste every day, or nearly 260 kilos per capita each year (France 24, 2017). Plastic bottles submerge the rivers of the Congo River, running through the city of Kinshasa. The water runs off there with difficulty (UN Environment Report, 2018). Plastic bottles, bottle caps, food packaging, plastic bags, lids, and plastic straws commonly use in Kinshasa and other cities in the DRC. This plastic waste is then dumped in garbage cans, gutters, and streams with adverse consequences for ecology and human health. The population and the abiotic environment suffer massive damage due to this plastic pollution in the light and Congolese authorities' interest. In Kinshasa, the DRC capital, plastic waste accumulates and invades the waterways of the Congo River. They prevent water from entering the ground during massive flooding and clog the pipes. Pollution also poses health problems (Bikay, 2018).

In Kinshasa, the Democratic Republic of Congo's capital, plastic waste invades the Congo River's soils and waterways. Bottles, bags, miscellaneous packaging garbage accumulates, clog pipes, and prevents water from entering the ground during massive flooding, sometimes resulting in some residents' death. The people of Kinshasa can't take it anymore and point the finger at the authorities. However, In December 2017, the government signed a decree. It prohibited the production, importation, marketing, and use of plastic packaging. It came into force in July 2018 but did not produce the desired outcome as it expected to reduce plastic waste pollution in DR Congo effectively.

The reason being, Article 2 of this decree declares the uselessness of this decree. It exempts from its application the main plastic products (water bottles and soft drinks), causing plastic pollution and contradicting the first article. Indeed, it is mention there, which follows: "Al.1. are not concerned by this decree, the production, the import, the marketing, and use: Bottles of water and non-alcoholic beverages plastic and small jars used for the packaging of certain products, food, and pharmaceuticals. Al.2. are not also affected by this decree, the import, and marketing of raw materials for the manufacture of products referred to in paragraph 1 of this article". Two contradictions emerge from an examination of the first two articles of this decree:

1) The production, marketing, and use of packaging for the sale of food, water, and drinks, including non-alcoholic drinks, prohibited in the first article are, as by a wave of a magic wand, not concerned or permitted by Article 2 of the 
same decree;

2) The import and marketing of raw materials for the manufacture of these water bottles and non-alcoholic drinks prohibited in the first article, then allowed in the second article, are allowed in the second article. In DRC, drinks alcoholic beverages are not in plastic bottles but instead glass.

Bottles of alcoholic beverages, therefore, do not cause plastic pollution. The bottles of soft drinks are the bottles of drinks that cause mainly plastic pollution. Therefore, it is ridiculous and malicious to do this demarcation of alcoholic drinks and bottles of non-alcoholic drinks.

By exempting bottles of water and non-alcoholic drinks, the Congolese legislator, legalizes, in fact, almost all plastic pollution in the DRC and exposes the population and the abiotic environment of the DRC to the unfortunate consequences of this pollution. This makes this decree empty and useless (Radio Okapi, 2018).

"More than twelve million people who consume at least one bottle a day; you can imagine the environmental chaos that this represents. So, if there are no initiatives, it is challenging to manage this problem.

\subsection{Research Hypothesis Development}

\subsubsection{Economic Factors}

The economic conditions of a country, an area, or a city may determine the extent of plastic waste pollution. Over the past decade, most developing countries have been struggling to curb the increasing rate of plastic waste pollution. Some have, however, developed specific measures to reduce the significant impact of pollution on their economy. Several studies have indicated the importance of economic factors in reducing the rate of plastic waste. Over the years, Kinshasa has introduced an increase in tax on plastic materials and relaxed taxes on paper products. This and other economic measures were put in place to help reduce the rate of plastic pollution in the city. Based on literature gather on plastic waste pollution, we propose the hypothesis that:

Hypothesis 1: Economic Factors have a positive impact on Plastic Waste Pollution Reduction in Kinshasa.

\subsubsection{Environmental Factors}

The environmental damage caused by inadequate waste management is significant; blocked drainage channels are the leading cause of death during floods because of the abundant amount of plastic materials in our rivers. Mismanagement of the Plastic Pollution in our rivers leads to mistreatment of water, which causes many cholera cases in Kinshasa, which is still a deadly disease. Enforcement of strict environmental control measures will help in reducing the rate of littering in Kinshasa. The availability of a well-demarcated refuse dump site will also help reduce environmental Pollution in Kinshasa.

Suppose we would use less plastic, recycle at home, and use a plastic alternative such as paper bags and other reusable products. In that case, we will be pro- 
tecting our environment and reducing plastic pollution. To examine how environmental factors contribute to curbing or controlling plastic waste pollution in Kinshasa, we proposed the following hypothesis:

Hypothesis 2: Environmental Factors have a significant positive impact on Plastic waste pollution reduction in Kinshasa.

\subsubsection{Government Policy}

Article 53 of the Democratic Republic of the Congo' (DRC) constitution states that "All persons have the right to a healthy environment that is favorable to their development. They must defend it. The State ensures the protection of the environment and the health of the population." The government should prevent plastic pollution and give its citizen a better environment. We can eliminate Plastic Waste if the government enacts strict policies to reduce plastic waste pollution. The government may introduce strict punishment for defaulters, closure of businesses, education on plastic waste pollution, and provision of effective refuse management processes. To establish the impact of government policies on plastic waste pollution reduction in Kinshasa, we formulate the following proposition:

Hypothesis 3: Government Policy has a significant positive impact on Plastic waste pollution reduction in Kinshasa.

\section{Research Methodology}

Our primary research interest is to examine the influencing factors of plastic waste pollution reduction in Kinshasa. This research is primarily a cross-sectional study that aims to examine how individual factors (such as Environmental, Government, and Economics) influence plastic waste pollution reduction in Kinshasa. The following subsections describe the research study area, sample size, research model, and questionnaire design.

\subsection{Description of Study Area}

Kinshasa is the capital and largest city of the Democratic Republic of the Congo (DRC), with an estimated population of 17,000,000 as of 2018. After Cairo and Lagos, the third most populated city in Africa, considered the largest Frenchspeaking agglomerations globally, having overtaken that of Paris. It is one of the most populated agglomerations in the world. The City-Province of Kinshasa covers $9965 \mathrm{~km}^{2}$ or $0.42 \%$ of the national territory. Located in the west of the country between 3.9- and 5.1-degrees south latitude and between 15.2- and 16.6degrees east longitudes, Kinshasa is limited:

- To the east by the provinces of Mai-Ndombe, Kwilu, and Kwango;

- To the west and north by the Congo River forming the border with the Republic of Congo Brazzaville;

- To the south by the province of Kongo Central.

Kinshasa has a tropical humid and dry climate (Aw) under the Köppen climate classification. Its long rainy season extends between June and September 
from October through July, with a comparatively short dry season. Kinshasa lies south of the equator, so its dry season starts during its June winter solstice. Unlike African cities further north that features this climate where the dry season usually starts around December. Kinshasa's dry season is marginally colder than its wet season, though year-round temperatures remain relatively constant. Kinshasa's hydrographic network includes the Congo River and its principal tributaries on the left bank, most of which navigate the city from south to north. They are the rivers Lukunga, Ndjili, Nsele, Bombo or Mai-Ndombe, and Mbale. These rivers are polluted because of a lack of proper sanitation and the city's demographic strain.

\subsection{Sample Size Determination}

A close-ended questionnaire was used for our survey. We used a simple random technique in selecting the respondents from the sample. The sample size refers to the number of units or people chosen from a larger group or unit from which the researcher wishes to gather data. Yamane's (1967) sample size determination approach was used to estimate our sample size from a target population of 800 Congolese residing in Kinshasa, as shown in Equation (1). A total of 267 questionnaires were distributed and returned for further analysis. We achieved a questionnaire recovery rate of $100 \%$.

$$
\begin{gathered}
n=\frac{N}{1+N(e)^{2}} \\
n=\frac{800}{1+800 *(0.05)^{2}}=266.67 \sim 267
\end{gathered}
$$

where: $n=$ sample size, $N=$ population of the study, $e=$ error parameter $(5 \%)$, $95 \%$ confidence level.

\subsection{Research Model}

To examine the extent of the impact of each of the influencing factors (economic, environmental, and Government policy) on plastic waste pollution reduction in Kinshasa, we proposed the research model, as shown in Figure 2. The model implies that pollution's influencing factors are the independent variables and plastic waste pollution reduction in Kinshasa is the dependent variable. The model also seeks to show the relationship between the influencing factors of pollution and plastic waste pollution reduction in Kinshasa by regressing the independent constructs (Economic factors, Environmental factors, and Government Policy) on the dependent constructs (Plastic waste pollution reduction in Kinshasa).

\subsection{Questionnaire Design and Measurement}

Research data was collected using a close-ended questionnaire, we obtained a total of 267 questionnaires after distributing in Kinshasa and used for further 


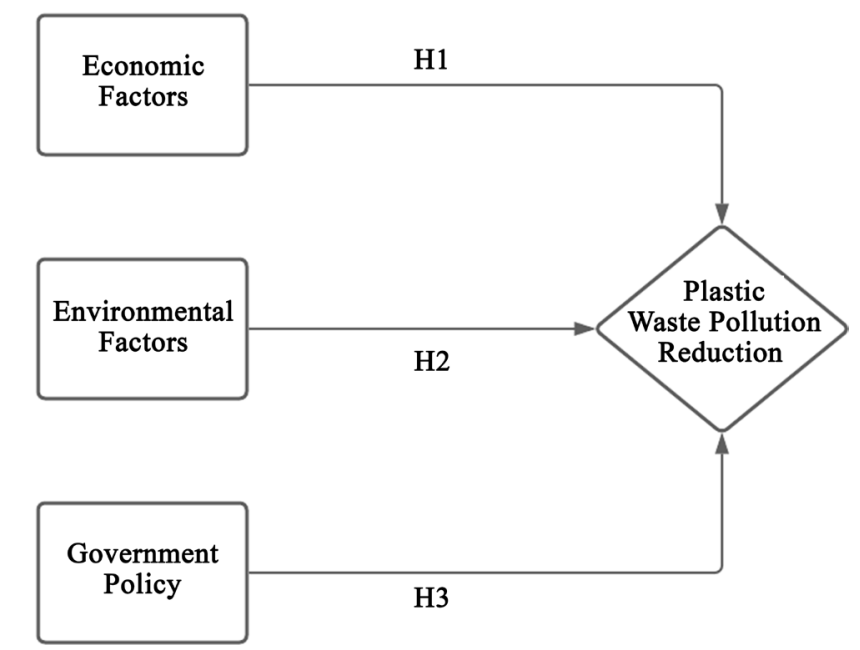

Figure 2. Research model (The research model shows how the independent variables connect to the dependent variable).

analysis. The questionnaire used for this study was adapted (Gündoğdu et al., 2018; Dilkes-Hoffman et al., 2019) and modified to represent our current study. The questionnaire was divided into two sections, with Section 1 consisting of measurement items on respondents' demographic profile. Section 2 consists of measurement items about how each of the pollution factors contributes to plastic waste pollution in Kinshasa. Responses were based on a five-point Likert scale where 1 = "Strongly agree", 2 = "Agree" 3 = "Neutral/ Not sure, 4 = "Disagree", 5 = "Strongly disagree". Plastic pollution has 4 measurement items; Government Policy and Environmental Factors both have 2 measurement items each. This was because 2 items were deleted from each of them to achieve reliability of questionnaire measurement. Economic Factors has 3 measurement items because we deleted 1 item to achieve a good reliability value. The final measurement items used for further analysis in our study are Plastic Pollution-4, Government Policy-2, Environmental Factors-2, and Economic Factors-3.

\subsection{Model Specification}

For our statistical analysis, we used IBM SPSS 25 to analyze our data. We used Multiple Linear Regression (MLR) analysis to evaluate the relationships that exist between the influencing factors of pollution and plastic waste pollution. Multiple Linear Regression (MLR) allows researchers to compute or evaluate the relationship between two or more independent variables and one dependent variable. Hence, MLR analysis is widely used in researches where relationships are to be established. For our study, the MLR model used to estimate the relationship between our variables is given as:

$$
Y_{i}=\beta_{0}+\beta_{1} \mathrm{GP}+\beta_{2} \mathrm{EVF}+\beta_{3} \mathrm{ECF}+\varepsilon_{i}
$$

where, $Y_{i}$ is the dependent variable (Plastic waste pollution reduction in Kinshasa), $\beta_{0}$ is constant and $\beta_{i}$ are the regression coefficient of the explanatory variables, $\varepsilon_{i}$ is the residual Error of regression. The independent variables are 
Government Policy (G.P.), Environmental Factors (EVF), and Economic Factors (ECF).

\section{Results and Discussion}

Our study's data were analyzed using the Statistical Package for Social Sciences (IBM SPSS version 25). We performed a descriptive analysis to understand more about the demographic characteristics of respondents under study. A Multiple Linear Regression (MLR) analysis was also performed to evaluate the relationship between the independent and dependent variables presented in our research model (Figure 2). The analyses consist of respondents' descriptive characteristics, correlation matrix, validity and reliability analyses, Multicollinearity and autocorrelation, and hypothesis testing. The results are presented in the subsections below.

\subsection{Descriptive Characteristics of Respondents}

We performed descriptive statistics on the respondents' data in our survey, and the results are shown in Table 1 . According to the results obtained, most of our respondents were male, and they account for $53.20 \%$, while the female respondents account for $46.80 \%$. At the same time, most of them fall between 18-25 years, representing $46.80 \%$, followed by those between the ages of 26-35years and $36-50$ years, accounting for $35.20 \%$ and $14.20 \%$, respectively. Respondents between the ages of 50 and above account for $2.2 \%$, while those below 18 years account for $1.5 \%$. Most of these respondents are graduates, and they account for $53.20 \%$, followed by the respondents, who are Post-graduates and Doctorate accounting for $34.10 \%$ and $11.24 \%$, respectively, while other educational levels account for $1.46 \% .67 .42 \%$ of the respondents are employed either in government institutions or the private sector, and $25.09 \%$ are unemployed. $7.49 \%$ of the respondents are doing their own business. In response to their monthly personal income status, majority of them earn below $\$ 1000$ (24\%), 20.20\% earn between $\$ 1000$ - \$2000, 14.20\% earn between \$2000 - \$3000, 11.20\% earn \$3000 - \$4000 and $8.20 \%$ and $22.10 \%$ earn between $\$ 4000$ - $\$ 5000$ and above $\$ 5000$ respectively.

\subsection{Reliability Test}

Hinton (2004) asserts that reliability always measures how well items in a questionnaire answer the respective questions and, more importantly, how well these items fit well together. Cronbach's alpha is the most widely used reliability statistic employed by many researchers to measure internal consistency reliability (Spiliotopoulou, 2009; Devon et al., 2007). Cronbach a coefficient values above 0.70 indicate good reliability (Bland \& Altman, 1997). The result in Table 2 shows that the estimated Cronbach $\alpha$ value ranged between $0.712-0.772$ for all scale of measurement variables implying a high correlation between the items and the questions; consequently, the questionnaire used for our study was consistently reliable. 
Table 1. Descriptive profile of respondents.

\begin{tabular}{|c|c|c|c|c|}
\hline Demographic Characteristic & Frequency & Percent & Valid Percent & Cumulative Percent \\
\hline \multicolumn{5}{|l|}{ Gender } \\
\hline Male & 142 & 53.20 & 53.20 & 53.20 \\
\hline Female & 125 & 46.80 & 46.80 & 100.00 \\
\hline Total & 267 & 100.00 & 100.00 & \\
\hline \multicolumn{5}{|l|}{ Educational Background } \\
\hline Graduate & 142 & 53.20 & 53.20 & 53.20 \\
\hline Post Graduate & 91 & 34.10 & 34.10 & 87.30 \\
\hline Doctorate & 30 & 11.24 & 11.24 & 98.54 \\
\hline Other & 4 & 1.46 & 1.46 & 100.00 \\
\hline Total & 267 & 100.00 & 100.00 & \\
\hline \multicolumn{5}{|l|}{ Age } \\
\hline Below 18 & 4 & 1.50 & 1.50 & 1.50 \\
\hline $18-25$ & 125 & 46.80 & 46.80 & 48.30 \\
\hline $26-35$ & 94 & 35.20 & 35.20 & 83.50 \\
\hline $36-50$ & 38 & 14.20 & 14.20 & 97.80 \\
\hline$>50$ & 6 & 2.20 & 2.20 & 100.00 \\
\hline Total & 267 & 100.00 & 100.00 & \\
\hline \multicolumn{5}{|l|}{ Employment } \\
\hline Employed & 180 & 67.42 & 67.42 & 67.42 \\
\hline Unemployed & 67 & 25.09 & 25.09 & 92.51 \\
\hline Personal business & 20 & 7.49 & 7.49 & 100.00 \\
\hline Total & 267 & 100.00 & 100.00 & \\
\hline \multicolumn{5}{|l|}{ Personal Income (\$) } \\
\hline Below $\$ 1000$ & 64 & 24.00 & 24.00 & 24.00 \\
\hline$\$ 1000-\$ 2000$ & 54 & 20.20 & 20.20 & 44.20 \\
\hline$\$ 2000-\$ 3000$ & 38 & 14.20 & 14.20 & 58.40 \\
\hline$\$ 3000-\$ 4000$ & 30 & 11.20 & 11.20 & 69.70 \\
\hline$\$ 4000-\$ 5000$ & 22 & 8.20 & 8.20 & 77.90 \\
\hline$>\$ 5000$ & 59 & 22.10 & 22.10 & 100.00 \\
\hline Total & 267 & 100.00 & 100.00 & \\
\hline
\end{tabular}

Table 2. Reliability test result.

\begin{tabular}{ccc}
\hline Variable & No of the measured items & Cronbach's Alpha \\
\hline Plastic Pollution & 4 & 0.772 \\
Government Policy & 2 & 0.724 \\
Environmental Factors & 2 & 0.765 \\
Economic Factors & 3 & 0.712 \\
\hline
\end{tabular}




\subsection{Construct Validity}

To test the sample data's construct validity, we used the maximum variance rotation proposed by Hair et al. (1998) for the principal component analysis (PCA). The results in Table 3 show a Kaiser-Meyer-Olkin(KMO) value of 0.847 , which is above the minimum acceptable value of 0.5 as proposed by Kaiser (1974), implying that the data from our survey met the condition (s) for principal component analysis. A total of three factors were extracted, and the variance proportions of each of the factors were satisfactory. The three factors extracted explained $65.37 \%$ of the variance (or Variations). The Bartlett's Sphericity value test was statistically significant $(P<0.05)$, indicating that our sample correlation matrix is not an identity matrix.

\subsection{Correlation Analysis}

Pearson's correlation coefficient statistic measures the statistical relationship between two continuous or quantitative variables (Rodgers and Nicewander, 1988). The general criteria for judging the magnitude and direction of the correlation coefficients according to Mukaka (2012) and Overholser \& Sowinski (2008) are as follows: a correlation coefficient between $0.00-0.10$ indicates negligible Correlation, between 0.10 - 0.39 indicates weak Correlation, between 0.40 - 0.69 indicates Moderate Correlation, and between 0.70 - 0.89 indicates Strong Correlation and a value between $0.90-1.00$ indicates a solid correlation. The result in Table 4 shows that all the correlation coefficients are significantly different from zero (0.224 - 0.645), indicating a form of association between the variables. The relationships between the variables are statistically significant since all the $\mathrm{P}$-values are less than 0.05 .

Table 3. Construct validity test.

\begin{tabular}{ccc}
\hline Test & Measure & Estimate \\
\hline Kaiser-Meyer-Olkin Measure of Sampling Adequacy & & 0.847 \\
Bartlett's Test of Sphericity & Approx. Chi-square & 1225.786 \\
& df & 55 \\
& Sig. & 0.00 \\
\hline
\end{tabular}

Table 4. Correlation matrix.

\begin{tabular}{ccccccc}
\hline \multirow{2}{*}{ Variable } & \multicolumn{6}{c}{ Correlation Matrix } \\
\cline { 2 - 7 } & Mean & Std. Dev & 1 & 2 & 3 & 4 \\
\hline Plastic Waste Pollution Reduc. & 10.48 & 3.13 & 0.000 & & & \\
Government Policy & 3.27 & 1.23 & $0.338^{* *}$ & 0.000 & & \\
Environmental Factors & 4.99 & 1.53 & $0.638^{* *}$ & $0.268^{* *}$ & 0.001 & \\
Economic Factors & 7.45 & 2.13 & $0.563^{* *}$ & $0.224^{* *}$ & $0.645^{* *}$ & 0.000 \\
\hline
\end{tabular}

${ }^{*}$ Correlation significant at the 0.01 level (2-tailed) and P-values in the diagonals. 


\subsection{Multiple Linear Regression (MLR) Analysis}

The multiple linear regression analysis results are presented in Table 5, Table 6 and Table 7.

\subsubsection{Model Summary}

Table 5 presents the model summary of our MLR analysis. The result indicates a multiple coefficient $(R)$ value of 0.687 and a coefficient of determination $\left(R^{2}\right)$ value of 0.472 . The coefficient of determination explains the degree of variation of the dependent variable by the predictor variables, indicating that about $47.2 \%$ of the variation in our dependent variable (Plastic Waste Pollution) was explained by our predictor variables (Government Policy, Environmental Factors, and Economic Factors). In contrast, the error term explains the rest of the variations. The F-Test value was statistically significant (F-test $=78.502, P<0.05)$, implying a satisfactory model fit. There was an indication of a moderate autocorrelation among the predictor variables with a Durbin-Watson value of 1.815. Field (2009) said that Durbin-Watson Values less than 1 and more than 3 are definite causes for concern. This means that the autocorrelation in our model is relatively standard and acceptable.

\subsubsection{ANOVA}

The result from Table 6 shows that our regression model is statistically significant (Sig. value-0.00) when the independent variables are regressed on the dependent variable. This further implies that our independent variables (Government Policy, Environmental Factors, and Economic Factors) are significant predictors of our dependent variable (Plastic Waste Pollution) in Kinshasa. It also indicates a satisfactory model fit.

Table 5. Summary of regression analysis.

\begin{tabular}{cc}
\hline Measure & Estimate \\
\hline $\mathrm{R}$ & 0.687 \\
R-square & 0.472 \\
Adjusted R-square & 0.466 \\
Standard Error of the estimate & 2.28318 \\
F-change & 78.502 \\
Sig. F & 0.000 \\
Durbin-Watson & 1.815 \\
\hline
\end{tabular}

Table 6. ANOVA table.

\begin{tabular}{cccccc}
\hline Model & Sum of squares & df & Mean square & F & Sig \\
\hline Regression & 1227.679 & 3 & 409.226 & 78.502 & 0.000 \\
Residual & 1370.995 & 263 & 5.213 & & \\
Total & 2598.674 & 266 & & & \\
\hline
\end{tabular}


Table 7. Table of coefficients estimates.

\begin{tabular}{cccccc}
\hline Variables & Estimate & T Value & Sig. Value & Tolerance & VIF \\
\hline Constant & 1.977 & 3.331 & 0.001 & & \\
Government Policy & 0.423 & 3.571 & 0.000 & 0.924 & 1.082 \\
Environmental Factors & 0.888 & 7.333 & 0.000 & 0.568 & 1.760 \\
Economic Factors & 0.360 & 4.172 & 0.000 & 0.581 & 1.720 \\
\hline
\end{tabular}

Dependent variable: Plastic Waste Pollution Reduction.

\subsubsection{Coefficient Estimates}

The result in Table 7 shows the estimated coefficients of our regression analysis. The result revealed that all the model variables are statistically significant at the 95\% confidence interval and positively impact the dependent variable. The $\mathrm{P}$-values of all variables are less than 0.05 ; Moreover, the T-values for all the variables are greater than the critical value of 1.96, indicating that our coefficient estimates are statistically significantly different from zero at the $95 \%$ confidence level. To examine Multicollinearity presence in our model, we estimated the Tolerance and Variance Inflation Factor (VIF) measures. Daoud (2017) recommended that a tolerance value less than 0.10 indicates the presence of Multicollinearity. Ringle et al. (2015) also recommended the minimum acceptable value of VIF to be 5 . The result in Table 7 indicates no presence of Multicollinearity in our model since values for Tolerance are greater than 0.10 , and VIF values are also less than the minimum acceptable value of 5 . The fitted model based on the coefficient estimates in Table 7 is presented in the equation below:

$$
\text { PWPR }=1.977+0.423(\mathrm{GP})+0.88(\mathrm{EVF})+0.360(\mathrm{ECF})
$$

where the dependent variable: Plastic Waste Pollution Reduction (PWPR). Predictor Variables: Government Policy (G.P.), Environmental Factors (EVF), Economic Factors (ECF).

\section{Conclusion}

This study highlighted some factors influencing the plastic pollution reduction in Kinshasa.

Though, every day almost 9,000 tons of garbage accumulate in Kinshasa, the Congolese capital does not have a functioning garbage collection system. Consequences for the health of the "Kinois" are catastrophic (made for minds 2020). Dozens of people in the Democratic Republic of the Congo die every year from flooding caused by rivers and sewage systems becoming blocked by plastic rubbish (Aljazeera, 2018). The government implemented the plastic ban in July 2018; there are still no adequate alternatives except biodegradable bags or imported paper packaging, which cost a lot more.

The analysis shows that the Economic Factors, Environmental Factors, and Government Policy are the key factors that can be implemented to reduce or mitigate plastic waste pollution in Kinshasa. These factors have a significant positive 
Table 8. Hypothesis decision table.

\begin{tabular}{cccccc}
\hline Hypothesis & Relationship & B coefficient & t-value & P-value & Decision \\
\hline H1 & EcF $\rightarrow$ PWPR & 0.360 & 4.172 & 0.000 & Supported \\
H2 & EnF $\rightarrow$ PWPR & 0.888 & 7.333 & 0.000 & Supported \\
H3 & GP $\rightarrow$ PWPR & 0.423 & 3.571 & 0.000 & Supported \\
\hline
\end{tabular}

impact on plastic waste pollution reduction in Kinshasa. The Environmental factors contribute the highest in reducing plastic waste pollution in Kinshasa, followed by Government Policy and then Economic Factors. This gives direction to policyholders and NGOs to prioritize implementing environmental measures to mitigate or reduce plastic waste pollution in Kinshasa.

\subsection{Hypothesis Testing \& Decision}

Results in Table 8 indicate the hypotheses proposed in our research supported by the quantitative analysis performed. Therefore, we can conclude that the factors proposed in this study for plastic waste pollution reduction can be implemented for positive results.

\subsection{Recommendation}

1) We recommend that the Government, NGOs, and other stakeholders in Kinshasa invest and develop an effective and proper waste management mechanism to mitigate the soaring rate of plastic waste pollution coupled with its negative consequences on Kinois.

2) We recommend that the government enforce a total ban on the importation and production of any sort of plastic materials such as plastic bottles, plastic bags, plastic food carriages, etc. This is because the partial ban does not seem to impact reducing plastic waste pollution in Kinshasa significantly.

3) We also recommend that the Government, NGOs, and other stakeholders sensitize and educate Kinshasa citizens on the negative consequences of littering and throwing rubbish or plastic waste materials into gutters and canals, rivers, and unapproved sites.

4) We also recommend that the government put in strict measures such as huge taxes, business closure, fines, and other sanctions on companies or individuals found polluting the environment, rivers, atmosphere, etc. This is to deter others from indulging in activities that will pollute the environment.

\section{Limitation and Directions for Future Research}

Though this research has studied the factors affecting the plastic waste proposal and attained some meaningful conclusions and findings, it has some limitations that can be addressed in future research. These limitations could provide direction for future studies. Since the research is a cross-sectional based study, extending the number of factors or variables and collecting more opposing or collaborative thinking is necessary. The sample target and the sample area should 
also be extended to make more generalized findings.

\section{Acknowledgements}

This work was financially supported by the Natural Science Foundation of Anhui Province (Grant No. 1908085ME127), National Natural Science Foundation of China (Grant No. 11872001), and the 2019 Graduate Innovation Fund Construction Project of Anhui University of Science and Technology (Grant No. 2019CX2052).

\section{Conflicts of Interest}

The authors declare no conflicts of interest regarding the publication of this paper.

\section{References}

Aljazeera (2018). The Deadly Cost of Dr. Congo's Pollution. https://www.aljazeera.com/news/2018/10/deadly-cost-dr-congos-pollution-1810021319 10842.html\#: :text=Dozens\%20of\%20people\%20in\%20the,more\%20needs\%20to\%20b e\%20done

Bai, M., \& Li, D. (2020). Quantity of Plastic Waste Input into the Ocean from China Based on a Material Flow Analysis Model. Anthropocene Coasts, 3, 1-5. https://doi.org/10.1139/anc-2018-0028

BBC News (2020). What Is the Problem with Plastic? https://www.bbc.co.uk/newsround/42810179

Bender, M. (2018). An Earth Law Solution to Ocean Plastic Pollution. Earth Law Center. https://www.earthlawcenter.org/blog-entries/2018/3/an-earth-law-solution-to-ocean-pl astic-pollution

Bikay, F. (2018). Amas de bouteilles plastiques flottantssur sur le fleuve Congo, Emissions Observateurs de France 24, Kinshasa, RDC, disponible depuis le 27 Avril 2017. https://youtu.be/x69z4lqu160

Bland, J. M., \& Altman, D. G. (1997). Statistics Notes: Cronbach's Alpha. BMJ, 314, 572. https://doi.org/10.1136/bmj.314.7080.572

Bond, T., Ferrandiz-Mas, V., Felipe-Sotelo, M., \& Sebille, E. V. (2018). The Occurrence and Degradation of Aquatic Plastic Litter Based on Polymer Physicochemical Properties: A Review. Critical Reviews in Environmental Science and Technology, 48, 685-722. https://doi.org/10.1080/10643389.2018.1483155

Chadar, S., \& Keerti, C. (2017). Solid Waste Pollution: A Hazard to Environment. Recent Advances in Petrochemical Science, 2, Article ID: 555586. https://doi.org/10.19080/RAPSCI.2017.02.555586

Daoud, J. I. (2017). Multicollinearity and Regression Analysis. Journal of Physics: Conference Series, 949, Article ID: 012009. https://doi.org/10.1088/1742-6596/949/1/012009

Demographia (2020). Demographia World Urban Areas-16th Annual Edition. http://www.demographia.com/db-worldua.pdf

Devon, H. A., Block, M. E., Moyle-Wright, P., Ernst, D. M., Hayden, S. J., Lazzara, D. J., Savoy, S. M., Kostas-Polston, E. (2007). A Psychometric Toolbox for Testing Validity and Reliability. Journal of Nursing Scholarship, 39.

https://doi.org/10.1111/j.1547-5069.2007.00161.x 
Dilkes-Hoffman, L. S., Pratt, S., Laycock, B., Ashworth, P., \& Lant, P. A. (2019). Public Attitudes towards Plastics. Resources, Conservation and Recycling, 147, 227-235. https://doi.org/10.1016/j.resconrec.2019.05.005

Eriksen, M., Lebreton, L. C. M., Carson, H. S., Thiel, M., Moore, C. J., Borerro, J. C., Galgani, F., Ryan, P. G., \& Reisser, J. (2014). Plastic Pollution in the World's Oceans: More than 5 Trillion Plastic Pieces Weighing over 250,000 Tons Afloat at Sea. PLoS ONE, 9, e111913. https://doi.org/10.1371/journal.pone.0111913

France 24 (2017). Pollution/République Démocratique du Congo, Une banquise de bouteille d'eau en plastique recouvre le fleuve Congo à Kinshasa, Emissions les Observateurs.

https://observers.france24.com/fr/20170509-une-banquise-bouteilles-plastique-recouvr e-fleuve-congo-kinshasa

Field, A. P. (2009). Discovering Statistics Using SPSS: and Sex and Drugs and Rock 'n' Roll (3rd edition). London: Sage.

Gall, S. C., \& Thompson, R. C. (2015). The Impact of Debris on Marine Life. Marine Pollution Bulletin, 92, 170-179. https://doi.org/10.1016/j.marpolbul.2014.12.041

Galloway, T. S. (2015). Micro- and Nano-Plastics and Human Health. In M. Bergmann, L. Gutow, \& M. Klages (Eds.), Marine Anthropogenic Litter (pp. 343-366). Berlin: Springer. https://doi.org/10.1007/978-3-319-16510-3 13

Gregory, M. R. (2009). Environmental Implications of Plastic Debris in Marine SettingsEntanglement, Ingestion, Smothering, Hangers-On, Hitch-Hiking, and Alien Invasions. Philosophical Transactions of the Royal Society B Biological Sciences, 364, 2013-2025. https://doi.org/10.1098/rstb.2008.0265

Gündoğdu, S., Yeşilyurt, İ. N., Erbaş, C., \& Gümüş, H. (2018). Survey on Awareness and Attitudes of Citizens Regarding Plastic Pollution in Hatay/Samandağ Turkey. International Marine Freshwater Sciences Symposium, Antalya, October 2018, 134-138.

Güven, O., Gökdağ, K., Jovanović, B., \& Kıdeyş, A. E. (2017). Microplastic Litter Composition of the Turkish Territorial Waters of the Mediterranean Sea, and Its Occurrence in the Gastrointestinal Tract of Fish. Environmental Pollution, 223, 286-294.

https://doi.org/10.1016/j.envpol.2017.01.025

Hammer, J., Kraak, M. H. S., \& Parsons, J. R. (2012). Plastics in the Marine Environment: The Dark Side of a Modern Gift. Reviews of Environmental Contamination and Toxicology, 220, 1-44. https://doi.org/10.1007/978-1-4614-3414-6 1

Hermabessiere, L., Dehaut, A., Paul-Pont, I., Lacroix, C., Jezequel, R., Soudant, P., \& Duflos, G. (2017). Occurrence and Effects of Plastic Additives on Marine Environments and Organisms: A Review. Chemosphere, 182, 781-793.

https://doi.org/10.1016/j.chemosphere.2017.05.096

Hester, R. E., \& Harrison, R. M. (2011). Marine Pollution and Human Health (p. 182). Cambridge: Royal Society of Chemistry.

Jambeck, J. R., Geyer, R., Wilcox, C., Siegler, T. R., Perryman, M., Andrady, A., \& Law, K. L. (2015). Plastic Waste Inputs from Land into the Ocean. Science, 347, 768-771. https://doi.org/10.1126/science.1260352

Kaiser, H. F. (1974). An Index of Factorial Simplicity Psychometrics. Psychometrika, 39, 31-36. https://doi.org/10.1007/BF02291575

Kershaw, P., Katsuhiko, S., Lee, S., Samseth, J., \& Woodring, D. (2011). Plastic Debris in the Ocean (pp. 20-33). United Nations Environmental Programme Year Book 2011.

Kühn, S., Rebolledo, E. L. B., \& Van Franeker, J. A. (2015). Deleterious Effects of Litter on Marine Life. In Marine Anthropogenic Litter (pp. 75-116). Cham: Springer.

https://doi.org/10.1007/978-3-319-16510-3 4 
Law, K. L. (2017). Plastics in the Marine Environment. Annual Review of Marine Science, 9, 205-229. https://doi.org/10.1146/annurev-marine-010816-060409

Li, W. C., Tse, H. F., \& Fok, L. (2016). Plastic Waste in the Marine Environment: A Review of Sources, Occurrence, and Effects. Science of the Total Environment, 566, 333-349. https://doi.org/10.1016/j.scitotenv.2016.05.084

Moore, C. (2020). Plastic Pollution. Chicago, IL: Encyclopædia Britannica, Inc. https://www.britannica.com/science/plastic-pollution

Moore, C. J. (2008). Synthetic Polymers in the Marine Environment: A Rapidly Increasing, Long-Term Threat. Environmental Research, 108, 131-139. https://doi.org/10.1016/j.envres.2008.07.025

Mukaka, M. M. (2012). Statistics Corner: A Guide to Appropriate Use of Correlation Coefficient in Medical Research. Malawi Medical Journal, 24, 69-71

Overholser, B. R., \& Sowinski, K. M. (2008). Biostatistics Preview: Part 2. Nutrition in Clinical Practice, 23, 76-84. https://doi.org/10.1177/011542650802300176

Parker, L. (2018). We Depend on Plastic. Now We're Drowning in It. National Geographic Magazine.

https://www.nationalgeograhic.com/magazine/2018/06/plastic-planet-waste-pollution-t rash-crisis

Radio Okapi (2018). Les sacs en plastique: Responsable de la pollution du sol et des cours d'eaux de la RDC.

https://www.radiookapi.net/2018/08/16/emissions/echos-pour-ledeveloppement/les-sa cs-en-plastique-responsable-de-la-pollution

Revel, M., Châtel, A., \& Mouneyrac, C. (2018). Micro (nano) Plastics: A Threat to Human Health? Current Opinion in Environmental Science \& Health, 1, 17-23. https://doi.org/10.1016/j.coesh.2017.10.003

RFI News (2019). Dr. Congo Entrepreneur Hope Clean Kinshasa. https://www.rfi.fr/en/africa/20190812-dr-congo-entrepreneurs-hope-clean-kinshasa

Ringle, C. M., Wende, S., \& Becker, J. M. (2015). SmartPLS 3. Bönningstedt, SmartPLS. http://www.smartpls.com

Rochman, C. M., Browne, M. A., Underwood, A. J., Van Franeker, J. A., Thompson, R. C., \& Amaral-Zettler, L. A. (2016). The Ecological Impacts of Marine Debris: Unraveling the Demonstrated Evidence from What Is Perceived. Ecology, 97, 302-312. https://doi.org/10.1890/14-2070.1

Spiliotopoulou, G. (2009). Reliability Reconsidered: Cronbach's Alpha and Paediatric Assessment in Occupational Therapy. Australian Occupational Therapy Journal, 56, 150155. https://doi.org/10.1111/j.1440-1630.2009.00785.x

UN Environment Report (2018). Notre Planète est étouffée par la pollution plastique, 2018. https://www.unenvironment.org/interactive/beat-plastic-pollution/fr

UNEP, NOAA (2011). The Honolulu Strategy: A Global Framework for Prevention and Management of Marine Debris. http://hdl.handle.net/20.500.11822/10670

Ville de Kinshasa (2012). Géographie de Kinshasa. https://web.archive.org/web/20120723091147/http:/www.kinshasa.cd/index.php?option $=$ com content $\&$ view $=$ article $\& i d=300$

Wang, J. J., Zheng, L. X., \& Li, J. H. (2018). A Critical Review on the Sources and Instruments of Marine Microplastics and Prospects on the Relevant Management in China. Waste Management \& Research, 36, 898-911.

https://doi.org/10.1177/0734242X18793504 
Windsor, F. M., Durance, I., Horton, A. A., Thompson, R. C., Tyler, C. R., \& Ormerod, S. J. (2019). A Catchment-Scale Perspective of Plastic Pollution. Global Change Biology, 25, 1207-1221. https://doi.org/10.1111/gcb.14572

Yamane, T. (1967). Statistics, An introductory Analysis (2nd ed.), New York, NY: Harper and Row.

Ziajahromi, S., Neale, P. A., Rintoul, L., \& Leusch, F. D. L. (2017). Wastewater Treatment Plants as a Pathway for Microplastics: Development of a New Approach to Sample Wastewater-Based Microplastics. Water Research, 112, 93-99.

https://doi.org/10.1016/j.watres.2017.01.042 